\title{
Hyperglycaemia, Pre-Diabetes and Diabesity: Can we Choose who to 'Fast-Track' into Diabetes Prevention?
}

\author{
Sally D Poppitt* \\ Human Nutrition Unit, School of Biological Sciences, Department of Medicine, University of Auckland, New Zealand
}

Submission: June 12, 2017; Published: June 15, 2017

*Corresponding author: Sally D Poppitt, School of Biological Sciences, University of Auckland, New Zealand, Tel: +64 (09) 630 5160;

Fax: +64 (09) 630 5764; Email: s.poppitt@auckland.ac.nz

\begin{abstract}
Global numbers of overweight and obesity have been increasing steadily for the past few decades, driving a rapid parallel increase in type 2 diabetes (T2D) morbidity and associated mortality. Hindered by our inability to clearly define the characteristics and therefore the assessment biomarkers for 'pre-diabetes', there remains significant difficulty in identifying those most at risk, essential in order to prioritize public health initiatives for those who would most benefit from 'fast-track' prevention. Implementation of a population-wide approach to T2D prevention is likely to be prohibitively expensive and unsuccessful, so more focused strategies are required. 'Pre-diabetes' is defined by any/all of 4 biomarker methods, comprising impaired fasting glucose (IFG), impaired glucose tolerance (IGT), IFG plus IGT, and mildly raised glycated haemoglobin (HbA1c). Each definition defines quite different sub-cohorts of the population, hence quite different risk profile, and may lead to both 'missed' and 'false positive' pre-diabetics. This problem must be resolved before we are able to make substantial strides and reliably choose who is most at risk and would most benefit from 'fast-track' into diabetes lifestyle and/or pharmaceutical prevention.
\end{abstract}

Keywords: HbA1c: glycated haemoglobin; Dysglycaemia; Pre-diabetes; Obesity; Type 2 diabetes; Prevention

Abbrevations: ADA: American Diabetes Association; T2D: Type 2 Diabetes; IFG: Impaired Fasting Glucose; IGT: Impaired Glucose Tolerance; WHO: World Health Organisation

\section{Opinion}

Despite considerable global efforts the number of people diagnosed each year with type 2 diabetes (T2D) continues to increase, hindered by our inability to both clearly define and to identify those most at risk, and therefore in turn to prioritise public health initiatives for those who could most benefit from 'fast-track' prevention. T2D is a disease with its origins in poor diet and lifestyle with excess weight gain and adiposity as the primary cause, and hence prevention of weight gain and/or weight loss is a central tenet to any prevention program. Global numbers of overweight and obesity have been increasing steadily for the past few decades [1-3], with little sign of slowing, despite significant global efforts to halt the increase, with the World Health Organisation (WHO) estimating that almost 2 billion adults have a body mass index (BMI) of $25 \mathrm{~kg} / \mathrm{m}^{2}$ or above [4]. In parallel T2D is becoming increasingly common [5]. In 1994 approximately 100 million people globally were reported with $\mathrm{T} 2 \mathrm{D}$, which increased to 382 million in 2013, and now with a projected increase to 592 million over the next 20 years [6]. Those who have high levels of central adiposity are at particular risk of T2D, with abdominal obesity strongly associated with important changes in body composition including lipid infiltration into critical organs such as pancreas and liver [7]. WHO also estimates that up to $80 \%$ of heart disease, stroke and T2D could be prevented by eliminating risk factors resulting from an unhealthy lifestyle [8], resulting in significant improvement both to the individual and national health care systems. In the US alone the medical consequences of obesity have been estimated to be in excess of US \$150billion each year [9].

Key to prevention is the identification of those who are most at risk and who are most likely to benefit from intervention. Certainly some success has been achieved by several large international programs investigating lifestyle and pharmaceutical (metformin) approaches for T2D prevention [10-13], yet the inexorable climb in patient numbers highlights the urgent continued problem. There is a strong fiscal argument 


\section{Current Research in Diabetes \& Obesity Journal}

against implementation of a population-wide approach, likely to be prohibitively expensive in many countries. Asia is an example of recent 'nutrition transition' to Westernized lifestyle, where T2D is a rapidly growing problem for many countries. China alone comprises a population of 1 billion, where up to $10 \%$ of adults are living with T2D and a further 30\% estimated to be overweight and at risk of later disease [14]. An alternate and likely more successful strategy is to identify these individuals who are at greatest risk of later development of T2D, commonly termed as those with 'pre-diabetes', and focus resources into prevention for these sub-cohorts of the wider population. A major problem with this strategy however is how to identify those who truly are high-risk, and who left untreated will develop T2D in the following years.

The term 'pre-diabetes' has been used since the 1950s [15], and today is defined using a (wide) variety of criteria set by several different international bodies [16-18]. In short, prediabetes may be identified in 4 main ways. Firstly, through raised fasting plasma glucose (isolated impaired fasting glucose, IFG), indicative of individuals who primarily have hepatic insulin resistance hence raised glucose concentrations resulting from increased gluconeogenesis and hepatic glucose output even in the fasting state; secondly through impaired glucose tolerance (isolated IGT) identified during a standardised 2 hour oral glucose tolerance test (OGTT), indicative of individuals who have insulin resistance at the site of skeletal muscle and hence poor insulin-mediated glucose disposal following consumption of a meal; thirdly those with both IFG and IGT; and fourthly those individuals who are identified with raised levels of glycated haemoglobin (HbA1c), more recently proposed by the American Diabetes Association (ADA) [17] as an indicator of prolonged raised glucose levels resulting from long-term exposure to both basal and post-meal hyperglycaemia, and potentially representative of the combination of adverse pathologies that underly IFG and IGT. However, HbA1c clearly identifies a different pool of individuals as pre-diabetic compared to those identified using glucose cut offs, in addition to effects of gender and ethnicity, possibly a result of differences in glycation and/or red cell survival.

Depending on the definition chosen, these tests identify very different populations with quite different aetiology of prediabetes [19] and it may be expected that they will have very different risks of converting to full blown T2D. Indeed Barry and colleagues (2017) have recently shown by meta-analysis that as these different tests for pre-diabetes define vastly different populations, significant misclassification does occur [20]. This results in two opposing outcomes where large numbers of individuals are either (i) 'missed' pre-diabetics who fail to be correctly identified as high risk and so not fast tracked for intervention, or (ii) 'false' pre-diabetics likely to take up lifestyle or pharmaceutical treatment unnecessarily. Clearly this problem must be resolved before we are able to make substantial strides and reliably choose who to 'fast-track' into diabetes prevention.

\section{Acknowledgement}

SDP holds the Fonterra Chair in Human Nutrition at the University of Auckland, and receives funding from MBIE National Science Challenge High Value Nutrition (HVN) program, NZ Health Research Council and Riddet CoRE.

\section{References}

1. NCD Risk Factor Collaboration (NCD-RisC) (2016) Trends in adult body mass index in 200 countries from 1975 to 2014: a pooled analysis of 1698 population-based measurement studies with 19.2 million participants. Lancet 387(10026): 1377-1396.

2. Ng M, Fleming T, Robinson M, Thomson B, Graetz N, et al. (2014) Global, regional, and national prevalence of overweight and obesity in children and adults during 1980-2013: a systematic analysis for the Global Burden of Disease Study 2013. Lancet 384(9945): 766-781.

3. The Global BMI Mortality Collaboration (2016) Body-mass index and all-cause mortality: individual participant-data meta-analysis of 239 prospective studies in four continents. Lancet 388(10046): 776-786.

4. World Health Organisation (WHO) (2016) http://www.who.int/ mediacentre/factsheets/fs311/en/.

5. International Diabetes Federation (IDF). Diabetes Atlas http:// wwwdiabetesatlasorg/resources/ 2015-atlashtml 2015;7th Edition.

6. Alberti KG, Zimmet PZ (2014) Diabetes: a look to the future. Lancet Diabetes Endocrinol 2(1): e1-e2.

7. Hill MJ, Metcalfe D, McTernan PG (2009) Obesity and diabetes: lipids, 'nowhere to run to'. Clin Sci 116(2): 113-123.

8. World Health Organisation (WHO). 2013-2020 Action plan for the global strategy for the prevention and control of noncommunicable diseases. http://wwwwhoint/nmh/ publications/ncd-action-plan/ en/ 2013; accessed June 2017

9. US Centres for Disease Control and Prevention (CDC).https://www. cdc.gov/media/matte/2012/05_weight_of_nation.

10. Knowler WC, Fowler SE, Hamman RF, Christophi CA, Hoffman HJ, et al. (2009) 10-year follow-up of diabetes incidence and weight loss in the diabetes prevention program outcomes study. Lancet 374(9702): $1677-1686$.

11. Li G, Zhang P, Wang J, An Y, Gong Q, et al. (2014) Cardiovascular mortality, all-cause mortality, and diabetes incidence after lifestyle intervention for people with impaired glucose tolerance in the Da Qing diabetes prevention study: A 23-year follow-up study. Lancet Diabetes Endocrinol 2(6): 474-480.

12. Lindström J, Peltonen M, Eriksson JG, Ilanne-Parikka P, Aunola S, et al. (2013) Improved lifestyle and decreased diabetes risk over 13 years: Long-term follow-up of the randomised Finnish diabetes prevention study (DPS). Diabetologia 56(2):284-293.

13. Liu AY, Silvestre MP, Poppitt SD (2015) Prevention of type 2 diabetes through lifestyle modification: is there a role for higher-protein diets? Adv Nutr 6(6): 665-673.

14. Yan S, Li J, Li S, Zhang B, Du S, et al. (2012) The expanding burden of cardiometabolic risk in China: the China Health and Nutrition Survey. Obes Rev 13(9): 810-821

15. Jackson WP (1952) Studies in pre-diabetes. Br Med J 2(4786): 690696.

16. International Expert Committee (2009) International Expert Committee report on the role of the $\mathrm{A} 1 \mathrm{C}$ assay in the diagnosis of diabetes. Diabetes Care 32(7): 1327-1334.

17. American Diabetes Association (2010) Diagnosis and classification of diabetes mellitus. Diabetes Care 33(1): S62-S69. 


\section{Current Research in Diabetes \& Obesity Journal}

18. Alberti KG, Zimmet PZ (1998) Definition, diagnosis and classification of diabetes mellitus and its complications: report of a WHO consultation. Part 1: Diagnosis and Classification of Diabetes Mellitus Provisional report of a WHO Consultation . Diabet Med 15(7):539-553.

19. Sequiera IR, Poppitt SD (2017) HbA1c as a marker of prediabetes: a reliable screening tool or not? Insights Nutrition Metab 1: 21-29.
20. Barry E, Roberts S, Oke J, Vijayaraghavan S, Normansell R, et al. (2017) Efficacy and effectiveness of screen and treat policies in prevention of type 2 diabetes: systematic review and meta-analysis of screening tests and interventions. BMJ 356: 16538.

Your next submission with Juniper Publishers will reach you the below assets

- Quality Editorial service

- Swift Peer Review

- Reprints availability

- E-prints Service

- Manuscript Podcast for convenient understanding

- Global attainment for your research

- Manuscript accessibility in different formats

( Pdf, E-pub, Full Text, Audio)

- Unceasing customer service

Track the below URL for one-step submission https://juniperpublishers.com/online-submission.php 